\title{
Contingencia, espontaneidad y libertad en Leibniz $^{1}$
}

\author{
Concha Roldán \\ concharoldan@gmail.com \\ Consejo Superior de Investigaciones Científicas (CSIC), Espanha
}

resumen La contingencia es para Leibniz, junto con la espontaneidad y la inteligencia, un componente esencial de la definición de la verdadera libertad, que nuestro pensador califica como uno de los problemas filosóficos por excelencia: "la cuestión de saber cómo se puede salir del laberinto, la gran cuestión de lo libre y lo necesario" (LEIBNIZ, 2007, Teodicea, 10, 11).

Leibniz, en diálogo con sus referentes polémicos (Descartes, Spinoza, Hobbes, Arnauld, King, Bayle, Clarke, entre otros) diferenciará -siguiendo la herencia agustiniana- entre el "libre albedrío" y la "verdadera libertad" o determinación racional, a la que sitúa en un camino intermedio entre el determinismo absoluto y la indiferencia de equilibrio. La libertad de los seres racionales será para Leibniz la condición sine qua non para entrar a formar parte del el reino de la gracia, un mundo moral dentro del mundo natural en el que impera el bien común.

palabras clave contingencia; libertad; necesidad; espontaneidad; determinismo; autonomía

\section{Preámbulo}

En uno de mis últimos artículos sobre Leibniz, defendía que uno de los aspectos más importantes que revierten en la importancia teórica de la Teodicea de Leibniz se cifra en haber abierto un espacio para la libertad humana (ROLDÁN y MORO, 2013). Generalmente, suele citarse a Leibniz cuando se quiere hacer historia de la teodicea en el pensamiento occidental como el creador del vocablo "teodicea" (justificación de 


\section{6}

Dios), para inmediatamente después "centrar" la cuestión de la teodicea en el problema del mal, como dedo acusador para un Dios pretendidamente bueno o, sencillamente, como una prueba de su inexistencia (ECHAVARRÍA, 2010). Ciertamente, Leibniz acunó el término y uno de sus méritos fundamentales fue atreverse a pedir al Dios cristiano -hasta entonces a salvo de toda sospecha- explicaciones sobre los resultados de su obra. Ahora bien, no podemos entender de manera reduccionista esta obra de Leibniz, una de las pocas que publicó en vida, en la que su intención era responder a las objeciones que le había planteado el escéptico Pierre Bayle, precisando sus propios argumentos sobre tres cuestiones fundamentales: la bondad de Dios, la libertad del hombre y el origen del mal, como subraya el subtítulo de los Ensayos de Teodicea. Por otra parte, podríamos afirmar sin temor a equivocarnos que los conceptos de bien y mal son la otra cara de la moneda de la libertad humana (en contraste con la libertad divina); por eso, tras un análisis de las distintas facetas del concepto de libertad leibniziano, el último apartado lo dedicaré a mostrar su propuesta del reino de la gracia como una encrucijada moral y política en la que el único camino "razonable" para el ser humano verdaderamente libre será combatir el mal/los males con la instauración del bien común.

El lugar preponderante que Leibniz concede en su obra a las nociones de libertad humana y de individuo es a mi entender la piedra angular de una ética de la responsabilidad y una política de la acción en el pensador de Leipzig, algo que pone claramente de manifiesto que para él "no todo estaba bien como estaba" (Cf. RUANO, 2008) -tal y como habitualmente se ridiculiza su denominado "optimismo"-, sino que más bien al contrario, el mundo era susceptible de perfeccionamientos y mejoras varias por parte de los seres humanos, en el complejo entramado de una armonía universal que no se sostenía sin la libertad como pieza clave de la misma. Aunque, sin duda, su horror por la indiferencia de equilibrio, hará que Leibniz sitúe por encima de las bondades del libre albedrío -con su posibilidad de elección entre un abanico de posibilidades- una libertad como "determinación racional por lo que consideramos lo mejor después de una deliberación racional” (Cf. ROLDÁN, 1990 b). Una determinación que de esta manera convierte a lo "razonable" humano en fuente de la pluralidad histórica, de lo bueno y lo malo. La historia -contingente por definición- es la otra cara de una naturaleza sorprendentemente 
matemática. Por eso, para Leibniz las grandes catástrofes o "los males físicos de factura no humana” (Cf. ROVIRA, p. 149) no serán la gran objeción de la teodicea -como luego harán los ilustrados, sobre todo Voltaire, inspirados en el terremoto de Lisboa de 1755-, cifrando su interés en la superación del mal moral y de los daños que éste causa. Para Leibniz, la defensa de una teodicea no está reñida con una ética de la responsabilidad, pues Dios -si existe- ha querido un mundo con libertad a sabiendas de que engendraría daño, como subraya Ignacio Sotelo (SOTELO, 1995, p. 221): "al concedernos la libertad, el mayor bien imaginable, Dios nos da la posibilidad, inherente a bien tan grande, de que la utilicemos mal".

El enfoque del problema de la libertad -que Leibniz califica como uno de los "laberintos" filosóficos por excelencia- es uno de los que se mantienen más constantes a lo largo de toda su obra, sin grandes modificaciones de interpretación desde sus escritos de juventud hasta los más maduros, en los que se observa únicamente una mayor precisión en la argumentación. Mi intención en estas líneas será tanto recoger el mantenimiento de sus convicciones filosóficas, como subrayar la originalidad de su planteamiento en los orígenes de la modernidad, sin por ello pretender minimizar la importancia de las disquisiciones leibnizianas en diálogo con la tradición escolástica (Suárez, Molina, Bañez, etc.), con los planteamientos de la Reforma luterana en torno a la predestinación -De servo arbitrio-, así como con sus referentes polémicos coetáneos (Descartes, Spinoza, Hobbes, Arnauld, King, Clarke, entre otros), con los que iniciamos el primer apartado.

\section{La libertad leibniziana entre el determinismo y el libre albe- drío: libertad como inclinación}

Durante todo el siglo XVII se suceden las polémicas en torno al tema de la libertad.Aunque las diferencias de matiz son grandes, podemos afirmar que las fuerzas se dividen fundamentalmente en dos grupos: los partidarios del determinismo y los defensores del libre albedrío. El determinismo en su vertiente filosófica encuentra su expresión en el escrito de Hobbes, Of Liberty and Necessity (1656), donde viene a sostener, a grandes rasgos, que es absurdo hablar de una libertad del querer, en cuanto que los motivos 
por los que escogemos no dependen de nuestra voluntad; la libertad puede ser sólo una libertad de hacer, si nada lo impide, esto es, una libertad exenta de coacción. Las tesis de Hobbes provocaron las objeciones de Bramhall, un defensor bastante moderado del libre albedrío, plasmadas en su ensayo A Defense of the True Liberty of Human Actions (1655), donde opone a la necesidad hobbesiana una necesidad moral que fundamenta los motivos internos de la voluntad, defendiendo una libertad del querer que oscila entre la indiferencia de la voluntad y el determinismo racional mediante el juicio del intelecto, que constituye el sentido mismo de la deliberación y fundamenta una acción orientada a la consecución de lo mejor. Hobbes respondió a su vez a los argumentos Bramhall defendiendo sus puntos de vista en Questions concerning Liberty, Necessity and Change (1656); y éste fue el texto que llegó a manos de Leibniz -con medio siglo de retraso, si nos apoyamos en el testimonio de una carta enviada a Coste el 8 de julio de 1711 (GP III, p. 419)-, interesándole hasta tal punto la obra del pensador inglés que se encargó de escribir una recensión del mismo, la cual vio la luz en 1710 como apéndice de su Teodicea, bajo el título de Réflexions sur l'ouvrage que M. Hobbes a publié en Anglois, de la Liberté, de la Necessité et du Hazard (LEIBNIZ, 1978,VI, pp. 388-399; cf. LEIBNIZ, 2007, 10, pp. 395-405; Cf. ROLDÁN, 1990 a, pp. 37-54).

No es mi intención hacer aquí un pormenorizado estudio histórico de la cuestión. Simplemente pretendo apuntar el enfoque que se daba en la época al problema de la libertad, para una mejor comprensión de las tesis leibnizianas. Recordemos en este sentido que Spinoza consideraba el libre arbitrio como una ficción, siendo la más alta expresión de la libertad el reconocimiento racional de la necesidad; "los hombres -dice en el Apéndice a la primera parte de la Ética- se creen libres, en cuanto que son conscientes de sus voliciones y deseos, e ignorantes de las causas que los disponen a querer y actuar"; por eso, no tiene sentido para él hablar de una libertad de querer, lo mismo que no lo tendría hablar de libertad de percibir o de desear; todo debe ser como es, porque no es posible que sea de otra manera, y nos hacemos libres en la medida en que nuestro conocimiento crece y nuestras acciones se convierten en un eslabón necesario de la infinita cadena de las causas naturales. El filósofo moral es para Spinoza ante todo un naturalista, que constata que no todos los hombres son libres por igual, pues la libertad no es una propiedad que caracteriza 
a los seres racionales, sino un proceso gradual que avanza paralelamente a nuestra adquisición de conocimiento, un proceso que no culmina nunca, puesto que hasta el hombre más sabio posee únicamente un conocimiento relativo; sólo Dios puede ser denominado libre porque existe en virtud de la sola necesidad de su naturaleza y se determina por sí solo a obrar, por lo que se conoce a sí mismo con la misma libertad y necesidad con que conoce todas las cosas que se siguen de su naturaleza (Ethica I, def. 7 y prop. XVII, cor. 2; cf. carta LVIII a Schuller, 1674).

Clarke, por su parte, quien se muestra como un digno crítico de Leibniz en la polémica sostenida con éste en los años 1715-1716, es un defensor comprometido del libre albedrío, adversario de Hobbes, Spinoza y Collins. Su postura quedaba clara en A Discourse Concerning the Being and Attributes of God (1705), pero se perfila en su refutación a una obra de Collins titulada Remarks upon a Book Entitled A Philosophical Inquiry concerning Human Liberty (1715). Clarke reivindica allí el poder activo del alma espiritual y su capacidad de determinarse voluntariamente según motivos que escapan a la inflexibilidad de las causas, para oponerse al materialismo y al mecanicismo que hacen del hombre una especie de objeto dotado de pensamiento; asimismo, distingue entre un orden moral y un orden natural que comparten la racionalidad, aunque el primero incluye la voluntad; y defiende que existe una conformidad del orden moral humano con la voluntad de Dios y el orden de la Naturaleza, aunque esto no significa que los actos humanos estén completamente determinados por una voluntad divina inexorable; la diferenciación de entendimiento y voluntad recrea en Clarke aquella oscilación entre voluntarismo y determinismo racional que ya veíamos en Bramhall. Aunque los puntos de acercamiento entre ambos en estas cuestiones son muchos, surgirá la discusión porque Clarke se erige en defensor de Newton, ante la acusación leibniziana de que su fisica había contribuido a corromper la religión natural.

En este breve repaso por los coetáneos de Leibniz, quiero referirme por último a la obra del obispo irlandés William King, fuertemente marcada por su reacción frente al escepticismo radical de Bayle. En su ensayo De origine mali (1702) refuta la tesis de que los actos y la elección están regidos por la necesidad, fundamentando su doctrina en el primado de la voluntad sobre el intelecto. Para ello, formula una doctrina de la indiferencia absoluta, según la cual reside en la voluntad el poder de escoger, 
creando con la elección la bondad misma del objeto al que se aplica; el intelecto tiene solamente una función coordinadora, pues su juicio sigue al movimiento de la voluntad, a cuyo servicio se encuentran los apetitos y sentidos. Leibniz considera la obra de King digna de mención y en sus Remarques sur le Livre de l'origine du mal -en lo sucesivo Remarques- señala que coincide con sus puntos de vista acerca del origen del mal en general y del mal fisico en particular, pero por lo que respecta a sus ideas sobre la libertad y el mal moral que de ella depende, encuentra que se oponen a sus propios principios, pues pretenden fundamentar la libertad en una indiferencia de equilibrio vaga y absoluta, que no supone ninguna razón para determinarse anterior a la determinación, ni en el que elige, ni en el objeto, sosteniendo que no se elige sino aquello que agrada, pero volviendo agradable a su vez lo que se elige, ya que se elige sin motivo (LEIBNIZ, 1978, \1,VI, p. 400; Cf. ROLDÁN, 1990 a, 124).

Aunque la postura leibniziana no es novedosa, presenta una indudable riqueza de elementos al pretender conciliar el libre albedrío con su peculiar determinismo. Leibniz afirma taxativamente que es partidario de una libertad que esté exenta no sólo de coacción, sino también de necesidad, algo que mantiene hasta sus obras de madurez como la Teodicea (LEIBNIZ, 1978,VI, \280, p. 283) o Causa Dei y subraya en su correspondencia de esa época, como se ve en una carta a Jaquelot del 28 de Abril de 1704 (LEIBNIZ, 1978, III, p. 473) y en una Carta a Coste del 19 Diciembre de 1707 (LEIBNIZ, 1978, III, p. 401). Para que una acción sea libre ha de carecer de coacción externa, pero esto no basta para definir la libertad, pues de lo contrario, habría que considerar libre a una pelota que se mueve sin impedimento en un horizonte continuado (LEIBNIZ, 1923,VI, II, 21, \96, p. 17); también ha de estar exenta de una necesidad absoluta, que no dejaría lugar a la elección (LEIBNIZ, 1978,VI, pp. 296 y 336), al permitir una única vía posible de actuación. Sin embargo, la oposición a la necesidad metafisica como expresión de la libertad no justifica para Leibniz que se opte por una indiferencia de equilibrio como alternativa: "Libertas indifferentiae est impossibilis" (Libertas est spontaneitas intelligentis, 1677: LEIBNIZ, 1978, VII, p. 109; Cf. LEIBNIZ, 1990 a, p. 208). Nada causa más horror a Leibniz que la opinión de aquellos que sostienen que la voluntad humana, para ser libre, puede y debe actuar sin motivos suficientes, haciendo caso omiso del influjo del entendimiento. 
Una indiferencia que presupone que no hay una razón mayor para hacer una cosa en lugar de otra, es para un Leibniz defensor del principio de razón suficiente (Cf. LEIBNIZ, 1903; LEIBNIZ, 1961; NICOLÁS, 1995; AGUADO, 2002) inconcebible, por lo que en su propia concepción opone a lo indiferente lo determinado: la determinación racional (Ibid.; LEIBNIZ, 1978,VII, p.108; LEIBNIZ, 1990, p. 208). De la misma manera que contrapone la contingencia a la necesidad, sustituye lo indiferente por lo determinado y lo meramente voluntario por lo que es fruto de una deliberación, como subraya en Conversation sur la liberté et le destin (16991703; LEIBNIZ, 1948, p. 478; LEIBNIZ, 1990, p. 23) o en Definición de libertad (1677): "Nuestras acciones están siempre determinadas y no son de ninguna manera indiferentes, pues siempre hay una razón que nos inclina -aunque no nos necesita- a hacer esto mejor que aquello; nada se hace sin razón, y nuestra libertad será mayor cuando más actuemos de acuerdo con la razón”(LEIBNIZ, 1978,VII, p. 109).

Aunque la oposición leibniziana a la concepción de la libertad como indiferencia de equilibrio se expresa con mayor claridad en su crítica al libro de King, y en algunas obras de madurez como los Nuevos Ensayos o la Teodicea, ya está perfilada su opinión en muchos escritos de juventud, como es el caso de Von der Allmacht und Allwissenheit Gottes und der Freiheit des Menschen (1670: LEIBNIZ,1923,VI 1, p. 545; LEIBNIZ, 1990 , p. 73) y Confessio philosophi (1673: LEIBNIZ, 1967), donde sostiene que se equivocan aquellos que afirman poseer una libertad tal que pueden elegir hacer o no hacer algo sin ninguna razón, pues esta misma obstinación constituye su razón (LEIBNIZ, 1923,VI, 3, p. 134).Y el propio Leibniz tiene un poderoso motivo para calificar como "quimera imposible" a la indiferencia de equilibrio, que atenta contra el principio de razón -que es el principio primario de todos nuestros racionamientos- (COUTURAT, 1902, p. 25), al autodefinirse como capacidad para actuar o no actuar, una vez dadas todas las condiciones de la acción -una concepción de la libertad que había sido defendida ya por Fonseca y Molina- (Cf. COUTURAT 1902, p. 15); esto es, que según unas premisas dadas, lo mismo puedo decidir hacer una cosa que su contraria, y no habría motivos, ni razones suficientes o determinantes que me llevaran a actuar, sino que mi puro arbitrio guiaría mi decisión por una de las alternativas. Un caso como el del famoso asno de Buridán, situado a igual distancia entre dos haces de 
avena sin poder decidir a cuál dirigirse para comer, es -según Leibnizuna ficción que nunca podría tener lugar en la realidad, aunque, si por un momento se supone que fuera cierto, habría que sostener que se dejaría morir de hambre (Teodicea SS 49 y 307: LEIBNIZ, 1978,VI, p. 129 y 298; Libertas est spontaneitas intelligentis: LEIBNIZ, 1978, VII, 111; LEIBNIZ, 1990, p. 209), pues en un hipotético caso de indiferencia absoluta no se podría elegir jamás (Teodicea \303: LEIBNIZ, 1978, VI, p. 296; carta a Coste, 19 Diciembre 1707: LEIBNIZ, 1978, III, p. 401). Pero el pobre asno sólo sucumbe de inanición en los libros de metafísica, porque en la realidad, siguiendo el principio de individuación, no pueden existir dos cosas idénticas, pues esto significaría - para Leibniz- que Dios es imperfecto y que ha actuado en la creación sin seguir el principio de razón suficiente, algo imposible para un ser racional perfecto (Nouveaux Essais, II, 27 \3: LEIBNIZ, 1923,VI 6, pp. 230-231; $4^{\circ}$ y $5^{\circ}$ Escrito a Clarke $\$ \$$ 1-6 y 25: LEIBNIZ, 1978,VII, pp. 371-372 y 394-395; Teodicea \$S 49 y 307: LEIBNIZ, 1978,VI, pp. 129 y 298).

Una indiferencia de equilibrio contradiría, además, la monadología leibniziana en su conjunto y el principio de continuidad. La mónada no puede estar un solo momento sin percepciones y apeticiones, de forma que el espíritu humano no está nunca inactivo, ni siquiera cuando está sumido en el más profundo de los sueños. Lo mismo que en la continuidad de la naturaleza no tiene cabida el vacío, las pausas, ni los saltos, tampoco se da nunca en el alma un momento de calma. Leibniz quiere trasladar el principio o "ley de continuidad" (Nouveaux Essais, IV, 16 \$12: LEIBNIZ, 1923, VI, 6, p. 473; LUNA, 1996) al terreno psicológico por medio de las "pequeñas pecepciones" (Nouveaux Essais, Prefacio: LEIBNIZ, 1923, VI, 6, pp. 54-55), inconscientes, inapreciables, pero en las que descansa la actividad ininterrumpida de nuestro espíritu. La mayoría de las veces -dice Leibniz- no las tomamos en consideración porque estamos acostumbrados a ellas, lo mismo que aquellas personas que viven al lado de un molino y no siempre perciben conscientemente aquel ruido que les es habitual. Pero tanto las percepciones conscientes como las inconscientes tienen su fundamento en el alma misma, y la decisión de la voluntad es el resultado de esa confluencia de fuerzas, del choque e tendencias contrapuestas, de la suma de inclinaciones y representaciones. Con la teoría de las pequeñas percepciones pretende Leibniz mostrar que, aún en el caso 
de que no conozcamos las razones que determinan nuestra actuación, eso no significa que no hay ningún motivo, tal y como escribe a Hartsoeker el 6 Febrero de 1711 (LEIBNIZ, 1978, III pp. 518-519). Incluso en los pequeños detalles de nuestra actividad cotidiana hay siempre razones que nos determinan, como, por ejemplo, cuando al salir de una habitación atravesamos el umbral primero con el pie derecho o con el pie izquierdo, o cuando al final de una alameda tomamos el camino de la derecha en vez del de la izquierda (Nouveaux Essais, II, 20 \$ 6: LEIBNIZ, 1923,VI 6, p. 166; Teodicea \ 46: LEIBNIZ, 1978,VI, p. 128).

La evidencia psicológica de la indiferencia, el que la sintamos o experimentemos en nosotros no es justificación suficiente de la misma, dirá Leibniz. Pero ¿quién nos garantiza que nuestra actuación está siempre motivada cuando no somos conscientes de esas razones? Es obvio que si estoy paseando por un jardín y, llegando a una bifurcación de caminos, veo que por el de la derecha avanza mi dentista -al que debo 5.000 euros desde hace un mes-, tomaré rápidamente el camino de la izquierda, o que si veo correr por el de la izquierda un perro -animal que me da pavor-, me dirigiré a la derecha; pero ¿cómo justificar mi elección si el jardín está desierto? La solución de las pequeñas percepciones es genial, pero sólo se justifica desde el presupuesto de una racionalidad universal, que es lo que se pretende demostrar: todas mis actuaciones tienen una razón que las determina, porque las razones están por todas partes. Leibniz no puede fundamentar su doctrina sino por el recurso a la trascendencia divina, al menos Dios podría dar siempre razón del partido que el hombre ha tomado, asignando a su decisión una causa o razón que le ha inclinado a optar por la misma, aunque para nosotros sea inconcebible (Teodicea $\$$ 49: LEIBNIZ, 1978,VI, p. 130). Un argumento del mismo tipo es el que utiliza contra King en sus Remarques $\ 27$; si el alma es perfectamente indiferente en su elección -dice- ¿cómo se explica la presciencia divina? (LEIBNIZ, 1978,VI, 434; 1990 a, p. 171), cuando, en rigor, un ser omnisciente podría también prever un comportamiento irracional.

Sin embargo, a pesar de la oposición a la indiferencia de equilibrio, admite Leibniz una cierta indiferencia, que se identifica con la contingencia y nos pone a salvo de la necesidad manteniendo la posibilidad de los opuestos, como subraya en sus Elements de réponse a Jablonski (1698; LEIBNIZ, 1948, p. 421). Nuestra libertad y la de todas las otras sustancias 


\section{4}

inteligentes, incluso Dios mismo, ha de estar acompañada de un cierto grado de indiferencia o contingencia, de forma que nunca estemos constreñidos con necesidad absoluta en nuestras actuaciones, puesto que lo contrario de lo que hacemos resta siempre posible y no implica contradicción -tal y como subraya en Conversation sur la liberté et le destin (aprox. 1699-1703; Cf. LEIBNIZ, 1990, p. 30). La indiferencia como contingencia o no-necesidad es un atributo característico de la libertad, pero no impide que haya una inclinación mayor por el partido que se elige, ni exige que se sea absoluta e igualmente indiferente por dos partidos posibles, pues esto significaría una especie de puro azar sin razón determinante, una quimera que no se encuentra en la naturaleza (Teodicea \$\$ 302-303: LEIBNIZ, 1978,VI, pp. 296-297). Hablando en términos absolutos, para Leibniz la voluntad es indiferente (Discurso de metafísica \$30: LEIBNIZ, 1978, IV, p. 454), pero con una indiferencia limitada que nos permite actuar o no actuar, o suspender nuestro juicio (Contra indifferentiam, 1697; LEIBNIZ, 1990, p. 120). Esto significa, si interpreto bien a Leibniz, que, una vez reunidos todos los requisitos o condiciones, puedo optar por no llevar a cabo ninguna actuación y dejar el juicio en suspenso, pero que, en caso de actuar, elegiré aquello a lo que mi deliberación me ha conducido -o inclinado- como lo mejor (Nouveaux Essais, II, 21 \23: LEIBNIZ, 1923,VI, 6, p. 181). Lo que viene a significar que nunca se da en la mente del agente libre tanta inclinación que se siga de ella necesariamente el acto, sin que medie el acto volitivo de la elección libre (LEIBNIZ, 1990, p.120). Así pues, en todas nuestras acciones subyacen razones determinantes que no nos constriñen a actuar como actuamos, sino que únicamente nos “inclinan” (Remarques \14: LEIBNIZ, 1978,VI, pp. 413-414; LEIBNIZ, 1990, p. 143). Si bien es cierto que el efecto seguirá a esta inclinación..., pero ¿en qué consiste esta inclinación? Para Leibniz, la voluntad es siempre un esfuerzo o inclinación al bien, siguiendo las razones que le proporcionan las diversas representaciones de la bondad de los objetos; el espíritu se inclina siempre del lado donde aparece el mayor bien presente (Nouveaux Essais, II, 21 \& 5: LEIBNIZ, 1923,VI, 6, p. 172 y Teodicea \$ 22: LEIBNIZ, 1978,VI, p. 115), aunque siempre podría elegir otro bien, pues actúa espontáneamente (Reflexions sur Bellarmin, aprox. 1680-1682; LEIBNIZ, 1948, p. 302), es decir, encuentra en sí mismo el principio de su determinación. En el caso de Dios, elegirá siempre lo objetivamente 
mejor, lo mismo que el sabio perfecto -si es que existe alguno-, mas no sucede lo mismo en el caso de las demás sustancias inteligentes, en las que a menudo las pasiones se mezclan con las razones verdaderas, por lo que elegirán simplemente el partido que mejor "les parece" aunque no "sea el mejor"; pero en ambos casos puede decirse que la elección sigue la inclinación mayor -como le escribe a Coste el 19 de diciembre de 1707 (LEIBNIZ, 1978, III, pp. 401-402). Cuanto más sabio es alguien, tanto más se ve determinado hacia lo más perfecto -subraya en De rerum originatione radicali (1697, LEIBNIZ, 1978,VII, p. 304) y más alejado se encuentra de la imperfección que conlleva la indeterminación o indiferencia, pero esto no significa que tenga una necesidad absoluta en su elección, pues un conocimiento claro y distinto de lo mejor determina la voluntad pero no la necesita (Teodicea \$ 310; LEIBNIZ, 1978,VI, p. 300).

Para Leibniz la voluntad actúa siempre por motivos, siguiendo la representación más ventajosa, pero nunca está obligada a seguir el juicio del entendimiento (Remarques \$13; LEIBNIZ, 1990, p. 142). De manera que el origen de los malentendidos de sus adversarios se encuentra en su confusión de una consecuencia necesaria absolutamente -cuyo contrario implica contradicción- con una consecuencia fundada sobre razones de conveniencia. Las acciones son libres y no necesarias, porque lo contrario de las mismas es lógicamente posible. Si decido ir a pasear, porque el buen tiempo me inclina a ello, esta acción -que hoy y ahora me voy a pasearha estado contenida desde siempre en mi concepto individual, lo que parece indicar la necesidad de la acción, pero para Leibniz es suficiente que sea concebible que no voy a pasear -lo cual no implica ninguna contradicción-, para que el acontecimiento no sea absolutamente necesario y mi acción sea libre.Y soy libre porque me he determinado a mí misma a actuar, siguiendo las representaciones de unos objetos que no se comportan conmigo como causas eficientes y fisicas, sino como causas finales y morales (Remarques $\$ 20$, LEIBNIZ, 1978,VI, p. 422; LEIBNIZ, 1900, p. 154). Pero, podríamos objetarle a Leibniz, ¿de qué me sirve una espontaneidad que no hace sino "seguir" mi propia naturaleza, que contiene en germen todo lo que voy a ser y a hacer? Analicemos en el siguiente apartado más pormenorizadamente en qué consiste ese concepto de "libertad racional" leibniziana, diametralmente opuesta a la libertad de indiferencia. 


\section{Construcción del concepto leibniziano de libertad como "deter- minación racional": contingencia, espontaneidad e inteligencia}

Leibniz es consciente de la ambigüedad del término "libertad" (Nouveaux Essais, II, 21 \$ 8; LEIBNIZ, 1923,VI, 6, p. 175), que ha constituido por ello una de los laberintos donde se han extraviado con frecuencia aquellos que han reflexionado sobre el tema, siendo así que su solución es básica para resolver muchos problemas de índole práctica (Teodicea Preface; LEIBNIZ, 1978,VI, p. 29). Desde su punto de vista, sólo hay una manera de salir del laberinto (Cf. ROLDÁN, 1990), y es conducir nuestros razonamientos con método, de forma que una especie de cálculo metafísico nos sirva de hilo de Ariadna (De primae philosophiae Emendatione; LEIBNIZ, 1978, IV, p. 469). En primer lugar, hay que precisar los términos, cosa que Leibniz hace marcando las diferencias entre los conceptos de "libertad", "contingencia" y "espontaneidad", por una parte, y "necesidad absoluta", "azar" (del que la "indiferencia de equilibrio" es expresión) y "coacción", por otra, tarea a la que él mismo considera haber dedicado su Teodicea (5 Escrito a Clarke; LEIBNIZ, 1978,VII, p. 389). Pero una vez situado el problema, esto es, una vez que hemos salido del laberinto, hay que enfrentarse con el Minotauro y explicar en qué consiste la libertad en sentido positivo.

Desde sus escritos de juventud, Leibniz se remonta a Aristóteles en la construcción de su concepto de libertad. Así, en la Confessio philosophi (1673; LEIBNIZ, 1923,VI, 3, p. 133) muestra su acuerdo con la definición aristotélica (Ética a Nicómaco, III, 2-3, 1111 a 22-1112 a 17), que habla de "espontaneidad" cuando el principio de actuación está en el agente, y de "libertad" cuando se trata de "espontaneidad con elección", con lo que un ser es más espontáneo cuanto más fluye su acto de su naturaleza y cuanto menos alterado está por las cosas externas, y es más libre cuanto más capaz es de elección, esto es, cuanto más pura y reposada sea la mente con que entiende; la espontaneidad tendrá que ver con la potencia y la libertad con el conocimiento. Esta misma idea podemos encontrarla en escritos de madurez, como la Teodicea (\$ 34; LEIBNIZ, 1978, VI, p. 122) o en su correspondencia, como, por ej., en la carta a Lady Masham de Septiembre de 1704, donde subraya -frente a Locke- que "la libertad exige que actuemos con espontaneidad y con capacidad de elección"( 
LEIBNIZ, 1978, III, p. 364). Otras veces sustituye el término "elección" por el de "deliberación" (Nouveaux Essais II, 21 \ 9; LEIBNIZ, 1923, VI 6, p. 176; o Causa Dei \20: LEIBNIZ, 1978,VI, p. 441).Y en ocasiones llega a hablar de libertad como "espontaneidad inteligente" (Libertas est spontaneitas intelligentis, 1677; LEIBNIZ, 1978, VII, p. 108; LEIBNIZ, 1990, p. 207), “espontaneidad racional” (COUTURAT, 1902, p. 25) o “espontaneidad consultante" (Ibid., p. 498). En cualquier caso, queda claro que la naturaleza de la voluntad requiere la libertad, y ésta consiste en que los actos voluntarios tengan su principio en el agente, acompañados de reflexión o razón (Causa Dei \& 20; LEIBNIZ, 1978, VI, p. 441), por lo que los animales, a pesar de tener en sí mismos su principio de acción, carecen de libertad. En este punto, se muestra Leibniz fiel al ya mencionado concepto aristotélico de libertad. Sin embargo, refiere Leibniz que los escolásticos exigen una tercera condición para que haya libertad, y es lo que llaman "indiferencia", cosa que, en su opinión, es preciso admitir siempre y cuando "indiferencia" signifique lo mismo que "contingencia", puesto que la libertad debe excluir una necesidad absoluta y metafisica -o lógica (Teodicea \301; LEIBNIZ, 1978, VI, p. 296; o Causa Dei \20; LEIBNIZ, 1978,VI, p. 44I). De forma que en el \& 288 de la Teodicea nos facilita lo que podríamos considerar una definición definitiva de libertad, en la que entran a formar parte los tres componentes, constituyendo la contingencia la base, la espontaneidad el cuerpo, y la inteligencia el alma de la libertad (LEIBNIZ, 1978,VI, p.288).

Intentemos ahora una mayor comprensión del concepto leibniziano de libertad analizando paulatinamente estos aspectos, algo que han despreciado Axelos y Gabaude, autores de dos de las grandes monografias modernas acerca de la libertad en Leibniz (Cf. ROLDÁN, 1984 y 1990).

\section{A. Contingencia}

La filosofia, la historia y la ciencia se construyeron, hasta fecha muy reciente, contra la contingencia, una idea que, de la mano de la postmodernidad, ha alcanzado un considerable protagonismo durante los últimos años (Cf. MORO, 2009). En la historia del pensamiento, el concepto de contingencia remite, en primer lugar, a la contraposición aristotélica entre lo contingente y lo necesario; siendo lo contingente aquello que puede o no puede acontecer y, por ello, remite a lo "casual" y "a lo que sucede 
por accidente", quedando por tanto desterrado del reino de lo racional. La exclusión de la contingencia del ámbito de lo explicativo quedó certificada algunos años más tarde de la mano de San Agustín de Hipona y de la filosofia cristiana de la historia. Dicha interpretación consideraba que la historia de la humanidad estaba predeterminada por un plan divino que, obviamente, anulaba el posible efecto de lo accidental en el devenir histórico (Cf. AGUSTIN DE HIPONA, De Civitate Dei, XIV-XXI; Cf. ROLDÁN, 1997, pp. 41-48).Y esta situación no cambió esencialmente con el desarrollo de la filosofia especulativa de la historia, perspectiva que se fue forjando gracias a autores como Leibniz, Voltaire, Vico y Herder y que alcanzó su apogeo a finales del siglo XVIII y a principios del siglo XIX de la mano de Kant, Hegel o Comte. Dicha filosofía tenía por pretensión explicar la historia de la humanidad apelando únicamente a la razón y, en este marco, lo contingente fue considerado incompatible con la explicación racional del pasado.

Pero centrémonos ahora en Leibniz y en el papel jugado por la contingencia en su teoría de la libertad. De una forma general había definido Leibniz lo contingente como aquello que no es absolutamente necesario, entendiendo por necesario aquello cuyo opuesto implica contradicción o es imposible ${ }^{2}$. En el mismo sentido, afirma que es contingente un acontecimiento cuyo opuesto es posible, mientras que es necesario aquel cuyo opuesto es imposible (Teodicea \282, LEIBNIZ, 1978, VI p. 284). Pero cuando se refiere a las acciones se limita a decir que todas son contingentes, aunque no por ello indiferentes (Libertas est spontaneitas intelligentis; LEIBNIZ, 1978,VII, p. 110; Cf. LEIBNIZ, 1990, p. 208), ni en el caso de Dios, que elige en razón de lo mejor, ni en el caso del hombre, que actúa de acuerdo con lo que mejor le parece -como subraya en la ya mencionada Carta a Coste del 19 Diciembre de 1707.

Pero ¿qué significa exactamente que en las acciones está excluida la necesidad lógica o metafísica? No sólo que estemos libres de coacción externa, como implicaría el que nos ataran de pies y manos o que nos colocaran al borde de un precipicio y nos empujaran, sino que nuestro espíritu pueda deliberar por su propia iniciativa (Teodicea $\$ 34$, LEIBNIZ, 1978,VI, p. 122), no habiendo un encadenamiento de necesidad entre la deliberación y la acción. Por lo general, se refiere Leibniz a la coacción como un principio externo (LEIBNIZ, 1978, VII, p. 108; Cf. LEIBNIZ, 
1990 a, p. 207) que nos impide hacer cuanto queremos; de esta manera, la prisión y las enfermedades coartan nuestra libertad impidiendo mover nuestro cuerpo y nuestros miembros de la forma que queremos y que ordinariamente podemos; así, ni Ana Bolena encerrada en la Torre de Londres, ni Enrique VIII aquejado de gota, tenían libertad de movimiento. Pero también con respecto al principio interno de libertad del querer puede darse, según la concepción leibniziana, una cierta coacción o coerción ejercida por el dominio de las pasiones, que introducen confusión en el espíritu, esclavizándolo y haciendo imperfecta la volición. Sin embargo, Leibniz alude en un sentido diferenciado a la libertad del querer, cuando se opone a la necesidad, cosa que aparece más claramente explicada en los Nuevos Ensayos (1705) que en el resto de sus escritos. La libertad del espíritu, opuesta a la necesidad, se refiere a la voluntad pura, en tanto que se distingue del entendimiento; es lo que comúnmente se denomina "libre arbitrio", y consiste en la pretensión de que el acto de la voluntad es contingente, aunque el entendimiento le aporte razones o impresiones fortísimas, ya que estas nunca constituyen una necesidad absoluta o metafisica (Nouveaux Essais, II, 21, \8: LEIBNIZ, 1923,VI, 6, p. 167).

La pregunta por la contingencia de las acciones se remite, pues, para Leibniz, a la libertad de la voluntad, esto es, a saber si en la misma existe suficiente independencia (Nouveaux Essais, II, 21, \21; LEIBNIZ, 1923, VI, 6, p. 181) o si, por el contrario, su dependencia del entendimiento imprime necesidad a la acción. En el caso del hombre, no se sigue siempre el último juicio del entendimiento práctico, aunque siempre se sigue del resultado de todas las razones y pasiones, determinándonos a querer aun sin juicio expreso del entendimiento (Teodicea $\$ 51$; LEIBNIZ, 1978, VI, p. 130). Sin embargo, ante la cuestión de si la voluntad de Dios no es libre pues sigue siempre el juicio del entendimiento, Leibniz responde que un conocimiento claro de lo mejor determina la voluntad, pero no la necesita (Teodicea \310; LEIBNIZ, 1978,VI, p. 300), aunque la esencia propia de la voluntad consista en el esfuerzo de actuar a partir de un juicio del entendimiento (Teodicea $\$ 311$; LEIBNIZ, 1978,VI, p. 301). Ahora bien, Leibniz considera a su vez, que una libertad divina absolutamente determinada por el entendimiento carecería de esa contingencia que ha de constituir la base de las acciones libres, por lo que sostendrá que Dios no deja de estar determinado por el entendimiento a elegir lo mejor, pero 
sin estar constreñido a hacerlo y sin que haya necesidad en el objeto de su elección, pues otras series de cosas permanecen igualmente posibles (Teodicea \45; LEIBNIZ, 1978, VI, p. 128). Pues afirmar que Dios no puede elegir más que lo mejor, sería como decir que lo que no elige es imposible, cuando -según ha definido- lo que es necesario lo es por su esencia, puesto que su opuesto implica contradicción $\left(5^{\circ}\right.$ escrito a Clarke \9; LEIBNIZ, 1978, VII, p. 390); si esto fuera así, se confundiría la necesidad moral, que procede de la elección de lo mejor, con la necesidad absoluta, y se trastocaría la voluntad con la potencia de Dios, cuando el Dios leibniziano "puede" producir todo posible, esto es, lo que no implica contradicción, pero "quiere" producir lo mejor entre los posibles (Ibid. \$S 73 y 76; LEIBNIZ, 1978,VII, pp. 408-409), en lo que se diferenciaría del Deus sive Natura spinozista, precisamente por el apoyo que el Principio de Perfección -en sí mismo contingente- supone para el Principio de Razón Suficiente (Cf. ROLDÁN, 1984 y 1989).

De acuerdo con esto, si la libertad del hombre consiste en poder zafarse del juicio del entendimiento, obtiene su libertad por defecto, ya que la suprema libertad no puede ser sino la divina. Por ello, Leibniz precisará a lo largo de sus escritos que el principio de lo mejor es el principio de lo contingente, porque permite que Dios elija la mejor de entre las posibilidades que se le ofrecen, y el hombre lo que le parece lo mejor entre varias cosas igualmente posibles ${ }^{3}$. Es un principio moral, que tiene su raíz en la bondad divina que decide conducirse al bien, atributo que corresponde a la voluntad divina con independencia de su entendimiento, el cual se rige por el principio lógico de no-contradicción; Dios no puede pensar lo contradictorio y quiere elegir lo mejor. Por esto, no sería imposible lógica o matemáticamente que Dios no eligiese el mejor mundo posible, pero eso significaría que sería un ser moralmente imperfecto, que actuaría por mero voluntarismo -o arbitrariamente, como Leibniz critica al Dios cartesiano. Para Leibniz, es obvio que la voluntad divina se dirige al bien, pues si no tuviese como regla el principio de lo mejor, se dirigiría al mal, que sería lo peor, o sería indiferente al bien y al mal y estaría guiada por el azar y, aunque sólo se abandonara al azar en algunos casos, sería imperfecta lo mismo que el objeto de su elección; en tal caso no merecería una confianza completa, porque actuaría sin razón y el gobierno del universo sería como ciertos juegos compuestos de razón y fortuna (Teodicea 
Apéndices; LEIBNIZ, 1978,VI, p. 386-387). El principio de perfección es un principio moral que a su vez permite dar razón de lo que existe y de la contingencia de las acciones divinas humanas.

La diferencia fundamental entre el principio de contradicción y el principio de perfección es que el primero trasciende al propio entendimiento divino, que no puede hacer que las verdades necesarias sean un producto arbitrario de su voluntad, mientras que el segundo nace de sí mismo, impulsado por el deseo de obrar bien; es por esto por lo que decimos que el principio de contradicción es para Leibniz, junto con el principio de razón suficiente, un principio necesario, mientras que el principio de perfección es un principio en sí mismo contingente, que depende del principio de contradicción y del principio de razón suficiente (1989). De esta manera, la conciliación de la contingencia de las acciones con su determinación por medio del principio de perfección no supone una contradicción dentro del pensamiento leibniziano, permitiéndole subrayar una cierta independencia de la voluntad con respecto al entendimiento, en cuanto que los motivos que determinan la acción inclinan sin necesitar, esto es, ejerciendo su influjo como causas finales y no como causas eficientes.

Sin embargo, no puede demostrarse que las acciones divinas $-y$ las nuestras por una especie de imitación- se fundamentan en el principio de perfección, haciéndolas determinadas y a la vez contingentes, por lo que la única prueba que tenemos de su contingencia es que otro tipo de actuación es concebible o está exenta de contradicción, lo que devuelve a la libertad un tinte lógico del que pretendía librarle el principio de perfección o de lo mejor. Sólo dos razones pueden darse, desde la concepción leibniziana, para defender la contingencia en la elección: que ésta sea una propiedad de la voluntad, o que no sea contradictorio suponer otras elecciones, porque son en sí mismas posibles. Pero esto equivaldría a decir que soy libre porque soy libre o, con un ejemplo, que no era necesario que fuera al cine, porque ir en su lugar al teatro era perfectamente concebible como no contradictorio.

La contingencia entonces se salva con la distinción entre lo posible y lo actual, pero tratándose de la libertad de elección no queda claro que existan realmente otras posibilidades de elección. Leibniz ha apelado a la contingencia como base de la libertad, sin embargo, la voluntad que 
requiere la libertad, consiste esencialmente en que las acciones sean espontáneas y deliberadas, aunque deben suponer una ausencia de necesidad “que destruiría la deliberación" (Causa Dei \$20; LEIBNIZ, 1978,VI, p. 441). La contingencia es, pues, una condición de la libertad que interesa en la medida en que facilita la deliberación del agente, ya que la razón es lo que define en última instancia al ser libre:"Hay contingencia en mil acciones de la naturaleza, pero si no se da el discernimiento en el que actúa, no hay libertad" (Teodicea $\ 34$; LEIBNIZ, 1978,VI, p.122).

\section{B. Espontaneidad}

Como mencionaba al principio de este capítulo, Leibniz no considera novedosa su definición de espontaneidad, que ya podía encontrarse en Aristóteles, aunque hace suya la tarea de establecer esta doctrina de forma sólida, dedicándole una atención que otros autores a su entender no le habían prestado (Teodicea $\int 59$; LEIBNIZ, 1978,VI, p. 135). No se cansa de repetir a lo largo de su obra (Cf. Confessio philosophi, 1673: LEIBNIZ, 1923, VI, 3, p. 133; Reflexions sur Bellarmin, aprox. 1680-1682: LEIBNIZ, 1948,, p. 301; Nouveau System, 1695: LEIBNIZ, 1978, IV, p. 484; Conversation sur la liberté et le destin, aprox.1699-1703: LEIBNIZ, 1948, p. 480; Table de définitions, modi agendi, aprox. 1702-1704: COUTURAT, 1901, p. 474; y Teodicea SS 290 y 301: LEIBNIZ, 1978,VI, p. 289)que espontáneo es aquello que tiene en sí mismo el principio o la fuente de su actividad, oponiéndolo a lo constreñido o sujeto a coacción y presentándolo como una forma de contingencia. Ahora bien, aunque la espontaneidad se fundamenta en la contingencia, puede haber expresiones de esta última que no hagan ninguna referencia a la primera, como por ejemplo el choque de dos bolas de billar o la enunciación de una verdad de hecho.

La teoría de la espontaneidad leibniziana sólo puede ser entendida en el marco de su monadología. No se trata de algo privativo del hombre, ya que es el denominador común de todas las sustancias simples (Teodicea \291; LEIBNIZ, 1978,VI 289; Discours de Métaphysique \32; LEIBNIZ, 1978, IV, p. 458; Monadologie \ 18; LEIBNIZ, 1978,VI, p .609-610; COUTURAT, 1902, p. 14), si bien es cierto que Leibniz afirma a veces que la espontaneidad corresponde en primer lugar a los espíritus, como escribe en su carta a Thomasius de 30 de Abril de 1669 (LEIBNIZ, 1923, II, 1, p. 20). Cada mónada es, en virtud de este principio interno, una especie de microcosmos 
autárquico, pues ninguna causa externa podría influir en estos cambios naturales que sólo en la propia mónada tienen origen (Monadologie \$\$ 11 y 56; LEIBNIZ, 1978,VI, p. 608 y p. 616). Cada sustancia contiene en su naturaleza la ley de continuación de la serie de sus operaciones, por lo que Leibniz se permite afirmar que se encuentra en ella de alguna manera todo lo que le ha sucedido y le sucederá, porque todas sus acciones proceden de su propio fondo, como escribe en una carta a Arnauld en 1688 (LEIBNIZ, 1978, II, p. 136); esta era la tesis del famoso $\ 13$ del Discurso de metafísica (1686) que había escandalizado al lógico de Port Royal (Cf. LEIBNIZ, 1990, XXXIV-XXXIX), por cuanto implicaría la supresión de la libertad de elección. Las mónadas serían completamente autónomas si exceptuásemos su dependencia de Dios (Discours de Métaphysique \32; LEIBNIZ, 1978, IV, p. 458; Teodicea \291; LEIBNIZ, 1978,VI, p. 290), único ser que puede crearlas y aniquilarlas (Monadologie $\$ 51$; LEIBNIZ, 1978,VI, p. 615). Así, "espontaneidad" viene a significar en última instancia que cada mónada creada no podría ejercer una influencia fisica en el interior de otra precisamente porque son independientes; por eso afirma Leibniz que la influencia de una mónada sobre otra no es más que ideal. Así, en sentido estricto, no puede encontrarse en las mónadas más que sus percepciones y sus cambios o apeticiones, por lo que las acciones son, en rigor, acciones internas (Monadologie $\ 17$; LEIBNIZ, 1978,VI, p. 609). Precisamente esta afirmación de la espontaneidad absoluta es lo que hará que peligre en la concepción leibniziana la existencia del mundo externo, en su afán por no colocar el principio de nuestras acciones fuera de nosotros (Teodicea \290; LEIBNIZ, 1978,VI, p. 289; Cf. SALAS, 1967). Ahora bien, todo el sistema de la armonía preestablecida es un reconocimiento implícito de la existencia de cosas exteriores a nosotros, con cuyos principios internos de actuación "concurrimos" o "armonizamos". Cada sustancia simple o mónada distinta constituye el centro de una sustancia compuesta, por ejemplo, de un animal, y el principio de su unicidad, estando rodeada por una masa compuesta de una infinidad de otras mónadas, que constituyen el cuerpo propio de esa "mónada dominante" encargada de "representar"-según las afecciones de ese cuerpo- las cosas que están fuera de ella; por eso decimos que un cuerpo orgánico no puede ser objeto de observación, siendo representado por cada mónada según su punto de vista, precisamente porque está dotada de acción interna; en las mónadas, las percepciones nacen unas 


\section{4}

de otras según las leyes de los apetitos o de las causas finales, mientras que los cambios de los cuerpos se suceden conforme a las leyes de las causas eficientes. Por eso, al tratarse de leyes diferentes, propugna Leibniz un sistema de "armonía preestablecida" entre el sistema de las causas eficientes y el de las causas finales, que garantice el acuerdo entre alma y cuerpo (Principes de la nature et de la Grace $\ 3$; LEIBNIZ, 1978,VI, p. 598-599; Monadologie SS 78-79; LEIBNIZ, 1978,VI, p. 620; Considerations sur les Principes de Vie, et sur les Natures Plastiques, par l'Auteur du Systeme de l'Harmonie preétablie, LEIBNIZ, 1978, VI, p. 542). Se trata de dos reinos naturales que actúan con absoluta independencia, pero "como si" uno influyese en el otro (Monadologie \81; LEIBNIZ, 1978,VI, p. 621;AGUADO,1993). En el fondo, se trata de una hipótesis -Leibniz nunca sostiene que sea otra cosa- que fundamente el conocimiento fenoménico aportando una certeza de que se veía privada la corriente empirista, aunque al otorgar un principio de vida incorporal a todos los seres orgánicos, introduce una riqueza en su planteamiento que no se deja reducir a un mero enfoque gnoseológico.

Todos los seres dotados de vida poseen para Leibniz espontaneidad, como expresión de una suficiencia o autarquía de sus respectivas sustancias simples, que son las fuentes de sus acciones internas; y este es el sentido en el que Leibniz habla de autómatas espirituales, capaces de "producir” percepciones (Monadologie \$18; LEIBNIZ, 1978, VI, p. 609-610). Sin embargo, aunque los animales (e incluso las plantas) estén dotados de espontaneidad, no por ello poseen libertad; aunque la estructura de las percepciones en los seres dotados de sensibilidad y memoria, carece del conocimiento reflexivo de ese estado interior o conciencia, constituido por la apercepción (Principes de la Nature et de la Grace \3; LEIBNIZ, 1978, VI, p. 600). La libertad es la "espontaneidad inteligente"; con lo que queda reducida en el mundo natural a los hombres: "Aquello que se denomina espontaneidad tanto en las bestias como en las otras sustancias privadas de inteligencia, cobra en el hombre su grado más alto de perfección y se llama libertad" (Libertas est spontaneitas intelligentis: LEIBNIZ, 1978,VII, 109; Cf. LEIBNIZ, 1990, p. 207). ${ }^{4}$

C. Inteligencia ó razón. Libertad humana y libertad divina.

Mientras la espontaneidad se refiere a la potencia para actuar, la inteligencia se refiere al conocimiento distinto del objeto de la deliberación 
(Teodicea \288, LEIBNIZ, 1978, VI, p. 288; LEIBNIZ, 1903, p. 496). Ambos aspectos difieren, dice Leibniz, como la especie respecto del género; por eso, decimos del ser humano que es libre en el mismo sentido que afirmamos que es "espontaneidad inteligente" o "espontaneidad racional” (COUTURAT, 1902, p. 25; AXELOS, 1973, p. 246) defiende, sin embargo, que sólo existe una diferencia de grado de algo que es cualitativamente idéntico, apoyándose en la expresión del opúsculo Libertas est spontaneitas intelligentis que acabamos de citar. En mi opinión, no puede hablarse de continuidad cualitativa, a pesar de la expresión leibniziana, o de mera diferencia de grado entre la espontaneidad y la libertad, aunque esta última suponga la anterior, lo mismo que la contingencia. Existe continuidad entre el hombre y los animales; de hecho el primero es -según Leibniz- animal en sus tres cuartas partes; pero la razón es algo que marca una diferencia fundamental entre el hombre y el resto de los componentes del reino natural (Principes de la Nature et de la Grace, fondés en raison-en lo sucesivo Principes- \4: LEIBNIZ, 1978,VI, pp. 599-600, y Monadologie \29: LEIBNIZ, 1978,VI, p. 611). Es cierto que Leibniz sugiere una diferenciación de grado cuando se refiere a la libertad, afirmando que ésta es mayor cuanto más se actúa de acuerdo con la razón (Libertas est spontaneitas intelligentis, LEIBNIZ, 1978,VII, 110; cf. LEIBNIZ, 1990, p. 208), pero sería absurdo desarrollar una teoría de la graduación de la espontaneidad, pues implicaría afirmar que algunas mónadas poseen un poco más o un poco menos en sí mismas el principio de su actividad. Podría hablarse quizá de una cierta continuidad en la diferencia gradual del conocimiento de un ser sólo dotado de memoria, que posee percepciones confusas, y un ser dotado de capacidad reflexiva, que tiene la capacidad de obtener percepciones distintas, aunque muchas veces sólo sean confusas; pero cuando se refiere Leibniz a la libertad, el conocimiento distinto del objeto de la deliberación, caracteriza además el comportamiento moral de un ser que tiene en sí mismo el principio de su actividad. La razón es "la verdadera raíz de la libertad" (Confessio philosophi, LEIBNIZ, 1923, VI 3, p. 135; Carta a Jaquelot, 28 Abril 1704: LEIBNIZ, 1978, III, p. 471; y Teodicea \288: LEIBNIZ, 1978,VI, p. 288), en la medida en que el ser racional puede determinarse a actuar tras una deliberación apoyada en el conocimiento distinto de todo, pues es su fuente, mientras que los hombres compartimos con el resto de las mónadas aquellas percepciones confusas 
que son el resultado de las impresiones que produce en nosotros todo el universo. Sin embargo, la concepción leibniziana abre ante los hombres un camino que está vedado al resto de las sustancias no inteligentes, en la medida que dispone de una creatividad, que imita la divina, permitiéndole colocarse por encima del resto de las mónadas: "Respecto del alma razonable o espíritu hay en él algo más que en las mónadas o en las simples almas. No es sólo un espejo del universo de las criaturas sino incluso una imagen de la divinidad. El espíritu no tiene sólo una percepción de las obras de Dios, sino que incluso es capaz de producir algo que se le parece aunque en pequeño... nuestra alma imita en su ámbito y en su pequeño mundo, en el que puede obrar lo que Dios hace en el grande" (Principes $\$$ 14: LEIBNIZ, 1978,VI, p. 604).

Según Leibniz, la raíz de la libertad en el hombre es ser imagen divina, pues Dios le ha querido crear libre, movido solamente por el bien considerado en sí mismo y para mayor gloria suya, consistiendo la única diferencia entre el creador y las criaturas en que Dios no puede equivocarse, mientras que el hombre está sometido a errores como consecuencia de la limitación original que le acompaña (Extraits de Bellarmin, 16801682: LEIBNIZ, 1948, p. 298; Discours de Métaphysique \ 28: LEIBNIZ, 1978, IV 453; COUTURAT, 1902, p. 15). Esta afirmación se sustenta en la aceptación de una verdad revelada: "Dios creó al hombre a su imagen y semejanza” (Génesis, I, 27; Teodicea \277: LEIBNIZ, 1978,VI, p. 282), apoyándose en la tradición agustiniana que entiende la libertad propiamente dicha (libertas) como la realización del bien con vistas a la beatitud. Así, siguiendo esta estela, Leibniz distinguirá entre la libertad frente la coacción (libertas a coactione) y la libertad de elección (liberum arbitrium), y la libertad propiamente dicha (libertas); las dos primeras son condiciones necesarias, pero no suficientes, para explicar la naturaleza de la verdadera libertad. La estructura general de la libertad humana no puede estar, pues, constituida de manera diferente a la divina, aunque habrá diferencias de grado, que descansan en el hecho de que toda obra divina es metafisicamente imperfecta, pues Dios no puede crear algo que sea idéntico a sí mismo. Sin embargo, Leibniz no puede partir de una verdad teológica, aunque su intención sea mostrar que verdad racional y verdad revelada no se contradicen. Por eso, parte de la libertad como de una ventaja que comparten las criaturas racionales, para elevarse a la presencia eminente 
de la misma en Dios (Teodicea $\$ 337$; LEIBNIZ, 1978, VI, p. 314), cuya existencia ha demostrado por diferentes vías y cuya esencia ha de contener los atributos humanos en forma de perfección (Monadologie $\ 48$ : LEIBNIZ, 1978, VI, p. 615). Le parece a Leibniz que Duns Scoto tenía razón al afirmar que, si Dios no fuese libre y sus acciones no estuvieran exentas de necesidad, tampoco sería libre ninguna criatura (Teodicea $\$ \$$ 232 y 337: LEIBNIZ, 1978,VI, pp. 255-256 y 315), pero la libertad debe ser explicada de modo tal que tenga su raíz en la naturaleza de la mente (o espíritu), porque sólo los espíritus son libres (Contra indifferentiam, 1697: LEIBNIZ, 1948, p. 384; Cf. LEIBNIZ, 1990, p. 119). El paralelismo entre la libertad divina y humana se remonta a uno de sus escritos de juventud, Von der Allmacht... (1671), donde afirma que existe una equivalencia entre la elección divina de lo mejor y la opción de la voluntad humana por el bien aparente (LEIBNIZ, 1923, VI 1, p .544-545; Cf. LEIBNIZ, 1990, pp. 70-73) y se prolonga en la Confessio philosophi (1673, LEIBNIZ, 1923, VI 3, p. 134-135) y en algunos escritos de 1677 (Conversatio cum Domino Episcopo Stenonio de libertate, 1677; Cf. LEIBNIZ, 1990, p. 177ss.; De libertate, LEIBNIZ, 1948, p. 276; cf. GRUA, 1953, p. 147) bajo el mismo signo, preocupándose por conciliar la libertad con una cierta necesidad -hipotética o moral- y fundamentando en el principio de razón su aversión por una indiferencia de equilibrio. Dios está determinado a elegir lo verdadera u objetivamente mejor y nosotros lo aparentemente mejor, pero ambos a título de una necesidad hipotética o por accidente (LEIBNIZ, 1948, pp. 273 y 276), que se explicará en el pensamiento maduro de Leibniz bajo la denominación de necesidad moral. La inclinación al bien constituye la razón suficiente que fundamenta la elección de todas las criaturas racionales, constituyendo su libertad: "Estar determinado por la razón a lo mejor, es ser el más libre” (Nouveaux Essais, II, 21 \$50: LEIBNIZ, 1923, VI, 6, p. 199; ibid. \$S 47, 48 y 49, LEIBNIZ, 1923,VI, 6, pp.195-199). Es propio de la naturaleza de la voluntad tender al bien y la libertad aumenta en relación proporcional a una determinación racional o conocimiento de los bienes verdaderos, despreciando los bienes aparentes: "Cuanto más se actúa siguiendo a la razón, tanto más libre se es" (Libertas est spontaneitas intelligentis: LEIBNIZ, 1978, VII, p. 109; Cf. LEIBNIZ, 1990, p. 208; Principes \14: LEIBNIZ, 1978,VI, p. 604; y Monadologie \29: LEIBNIZ, 1978,VI, p. 611). La razón es la condición de posibilidad de la libertad que 
comparten Dios y los hombres -y cualquier hipotética criatura espiritual-, pero sólo Dios está en posesión de una libertad absoluta (The System of grace and Greewill, 1705: LEIBNIZ, 1948, p. 254), mientras que nosotros estamos en parte inmersos en la esclavitud, porque nuestras percepciones o representaciones del bien son confusas, como escribe a la princesa Sofia en Junio de 1700 (LEIBNIZ, 1978, VII, p. 556; cf. Teodicea \289: LEIBNIZ, 1978,VI, p. 288-289). El hombre puede, pues, actuar según la razón y entonces es libre, porque actúa según las perfecciones de su propia naturaleza, pero puede dejarse llevar por las pasiones convirtiéndose en esclavo de las cosas externas (Libertas est spontaneitas intelligentis: LEIBNIZ, 1978,VII, p. 109; Cf. LEIBNIZ, 1990, p. 208). Se trata de una degradación del ser humano dentro de la jerarquía de los seres vivos; sin embargo, no puede entenderse esta esclavitud de las cosas externas como una influencia directa de las mismas.

Cada alma animal es autónoma y espontánea, no existiendo interacción de unas a otras, por lo que Leibniz no puede entender por pasiones más que las representaciones o percepciones confusas del mundo, o las razones falsas o erróneas - algo muy socrático- que entran a formar parte en nuestras deliberaciones (Conversation sur la liberté et le destin, 16991703: LEIBNIZ, 1948, p. 479; Cf. LEIBNIZ, 1990, p. 25). Pero esto nos 1leva al problema que planteábamos al final del epígrafe pasado, ¿cuál es el motivo por el que unos hombres actúan según rectas razones y otros no?, ¿su propia libertad? ¿Cómo puede identificarse entonces libertad con actuación racional? Estas cuestiones llevarían a plantear problemas a la doctrina leibniziana del pecado como fruto de la responsabilidad humana, pues, si al dejarnos llevar por las pasiones no somos libres, ¿cómo podemos ser responsables? Judas se dejó llevar por la avaricia, traicionando a Cristo para conseguir treinta monedas de plata; no actuó racionalmente porque antepuso el brillo de las monedas al bien moral que significa no traicionar a un amigo: ¿fue, no obstante, libre y responsable? Para responder a estas preguntas me parece que hay que distinguir en Leibniz dos aspectos diferentes de la libertad. Por una parte, se identifica con libertad de elección, esto es, libre arbitrio o esa cierta contingencia que subyace a toda acción; este es el sentido en el que afirma que, por muy grande que sea la corrupción humana, la libertad permanece a salvo, pues aunque el hombre haya de pecar, nunca es necesario que cometa ese acto (Causa 
Dei $\int S 101$ y 104: LEIBNIZ, 1978, VI, p. 454). Por otra parte, el grado sumo de libertad se identifica con la suprema determinación racional por lo mejor, libertad que sólo posee Dios, pero esto no significa que algún hombre pueda estar privado de inteligencia, porque es lo que constituye su propia naturaleza (Libertas est spontaneitas intelligentis: LEIBNIZ, 1978, VII, p. 109; Cf. LEIBNIZ, 1990 a, p. 208); la acción voluntaria ha de incluir espontaneidad y deliberación, y excluir una necesidad absoluta, para que pueda 1lamarse libre y responsable (Causa Dei \$ 20: LEIBNIZ, 1978, VI, p. 443). Dejando al margen que Dios previera la actuación de Judas, éste pudo elegir y, además, sopesó una serie de razones en su elección, optando por lo que se le representaba como el mayor bien aparente, luego fue libre, aunque su libertad estuviera ensombrecida por la confusión de sus pensamientos. Pero resta por resolver una cuestión, a saber, por qué unos hombres actúan racionalmente y otros no. No creo que Leibniz admitiese que la capacidad racional es otorgada con diferencia de grado a los distintos seres humanos. Todos la reciben por igual, sólo que unos "eligen" ejercitarla y otros no, de acuerdo con la claridad de sus percepciones; e incluso los más sabios cometen errores, porque es un defecto connatural a la razón humana que no pueda permanecer siempre atenta; lo mismo que un matemático comete errores de cálculo, muy a menudo sucede que realicemos lo que no es debido u omitamos lo debido (Animadversionesin partem generalem Principiorum Cartesianorum: LEIBNIZ, 1978, IV, p. 362). La diferencia entre los errores y los pecados es que en el último caso el espíritu se aparte deliberadamente de la atención necesaria (Confessio philosophi: LEIBNIZ, 1923,VI 3, p. 135; y Diálogo entre un político sagaz y un sacerdote de reconocida piedad, 1679: LEIBNIZ, 1982, p. 223), porque, por más eficaz que sea la gracia divina, podemos resistirnos a ella (Teodicea $\$ \$$ 279 y 280: LEIBNIZ, 1978,VI, pp. 282-283). De esta manera, no somos libres -en el sentido positivo del término- cuando desdeñamos de forma insensata la naturaleza y los privilegios que nos han sido otorgados, porque no nos consideramos suficientemente libres sin el poder de la irracionalidad, a pesar de que lo propio de la suprema libertad es el empleo de la razón (Confessio philosophi: LEIBNIZ, 1923, VI 3, p. 135); mientras que somos libres por excelencia cuando empleamos nuestras luces para ordenar las cosas del mejor modo posible, colaborando así con el plan divino, pues -y eso es lo alarmante aunque todo va a ir del mejor modo sin 
nosotros, gozaremos de la buena marcha de las cosas conforme a nuestra buena voluntad (Von der Weisheit, 1694-1698: LEIBNIZ, 1948, p. 287). Sin embargo, siempre conservamos el libre albedrío suficiente para inclinar la balanza de nuestra deliberación por motivos irracionales, y en ambos casos contribuimos a que se cumpla la armonía universal.

Por otra parte, se le plantea a Leibniz la cuestión de si Dios es libre, ya que no puede dejar de elegir lo mejor. En la Confessio philosophi afirma que la libertad de Dios es suprema, aunque no puede errar en la elección de lo mejor (LEIBNIZ, 1923,VI 3, p. 135).Y en el apéndice de la Teodicea, reducido a forma de argumentos, niega la premisa: "Quien no puede dejar de elegir lo mejor, no es libre", explicando que la verdadera y perfecta libertad consiste en que uno pueda emplear lo mejor posible su libre arbitrio, porque nada es menos servil y más conveniente al grado más alto de la libertad que conducirse siempre al bien según su propia inclinación (Teodicea Apéndices: LEIBNIZ, 1978, VI, pp. 385-386). La indeterminación o indiferencia absoluta, lejos de ser un privilegio, es un absurdo, y Dios mismo, que es el ser más perfecto, es también el más determinado a actuar de la manera más conforme a la suprema razón (Conversation sur la liberté et le destin, GRUA, p. 480). Dios no quiere nada sin razón; en rigor, su voluntad está determinada por una razón que la precede (De libertate, 1677: LEIBNIZ, 1948, p. 276; Discours de Métaphysique \$S 2 y 3: LEIBNIZ, 1978, IV, pp. 428-429; Causa Dei \$S 19 y 77: LEIBNIZ, 1978,VI, pp. 441 y 450; Monadologie \53: LEIBNIZ, 1978,VI, p. 616). La razón fundamenta la voluntad divina, constituyendo una de sus perfecciones (Definitiones a su proyecto de Scientia generalis: LEIBNIZ, 1978,VII, p. 74). Incluso la bondad y justicia divinas serían denominaciones extrínsecas, si su verdad descansase "solamente" en la voluntad divina (Unvorgreiffliches Bedencken, 16981701: LEIBNIZ, 1948, p. 433); sin embargo, con este "solamente" quiere Leibniz indicar que, aunque Dios únicamente puede actuar en perfección de acuerdo con la razón (Discours de Métaphysique \3: LEIBNIZ, 1978, IV, p. 429), se da un equilibrio entre razón y voluntad, pues ser libre es estar determinado por la razón a lo mejor, pero esto presupone a su vez la voluntad divina de actuar del mejor modo posible: "Deus vult optima" (Carta a Bernoulli, 21 Febrero, 1699: LEIBNIZ, 1978, III, p. 574). La contingencia de las acciones divinas se fundamenta en la contingencia del principio de perfección, pero una vez que Dios ha decidido actuar de acuerdo con este 
principio, se somete al discernimiento de su perfecta razón; en este sentido, podría aplicársele el semel iussit, semper paret de Séneca (De providentia, 5), porque obedece a las leyes que ha querido prescribirse, aunque el propio Leibniz afirma que habría hecho mejor en decir que Dios manda siempre y siempre es obedecido, pues su voluntad permanece siempre la misma. Sin embargo, Leibniz quiere subrayar también una libertad de elección en Dios -equivalente al libre arbitrio humano de que he hablado- que justifique la contingencia de las cosas, apoyándose en las posibilidades que nunca se actualizan: "Sin embargo, aunque su voluntad (de Dios) sea siempre infalible y tienda siempre a lo mejor, el mal o el menor bien que rechaza, no deja de ser posible en sí; en caso contrario, la necesidad del bien sería geométrica, por así decirlo, o metafísica, y completamente absoluta; la contingencia de las cosas sería destruida y no habría elección" (Teodicea Apéndices: LEIBNIZ, 1978,VI, p. 386; LEIBNIZ, 2007, 10, pp. 393-394). Desde mi punto de vista, esto refleja la desconfianza leibnizana en que la contingencia del principio de perfección (1989) baste para fundamentar la libertad divina, esto es, la contingencia de su acción. Por una parte, la suprema y positiva libertad divina consiste en estar determinado por la razón a lo mejor, pero, por otra parte, Dios estaría necesitado en su elección si no pudiera elegir entre diversas posibilidades; Dios no deja de elegir lo mejor, pero no está obligado a hacerlo, pues otra serie de cosas es igualmente posible (Teodicea SS 45 y 235: LEIBNIZ, 1978, VI, pp. 128 y 257-258). Posibilidad y contingencia en la elección constituyen, pues, condiciones para que pueda hablarse de libertad divina: "Radix libertatis in Deo est rerum possibilitas sive contingentia, qua fit ut innumera reperiantur quae neque sunt necessaria neque impossibilia, ex quibus Deus illa eligit quae ad gloriam suam testandam maxime faciunt" (Extraits de Bellarmin, 1680-1682: LEIBNIZ, 1948, p. 298). Dios también ha elegido entre diversos partidos posibles, luego metafísicamente hablando podría elegir lo que no fuese lo mejor, pero no podría hacerlo desde un punto de vista moral (Teodicea $\$$ 234: LEIBNIZ, 1978, VI, p. 256). No era imposible que Dios crease otro mundo, porque no hay más imposible para Leibniz que lo contradictorio (Ibid. p. 257). Otros mundos son en sí mismos posibles, sin embargo, queda abierta la pregunta de si la libertad práctica y la contingencia real pueden fundamentarse en la ausencia de contradicción lógica. 
En resumen, hemos visto que el concepto de libertad leibniziano está construido en forma piramidal, colocando en su base la contingencia, en su tronco la espontaneidad y la razón en la cúspide, estructura que jerarquiza a su vez la perfección gradual de las mónadas. El grado sumo de libertad corresponde sólo a Dios, pero la determinación racional alcanza a todos los espíritus, puesto que tienen capacidad de seguir el mandato de su razón. Se trata de un cierto determinismo que, sin embargo, no recae en el necesitarismo que Leibniz pretende evitar, no tanto porque concurran a la acción motivos irracionales, cuanto porque estos actúan como causas finales que inclinan a la voluntad desde dentro. Podemos decir que Leibniz es coherente con sus presupuestos y que, de acuerdo con su doctrina de la libertad, no es contradictoria su afirmación: "Datur media inter necessaria et fortuita, nempe liberum” (LEIBNIZ, 1854, p. 48), aunque el fiel de la balanza se encuentre sometido por el propio Leibniz a diversas oscilaciones, según defienda su teoría frente a partidarios de una necesidad o una indiferencia absoluta, respectivamente.

Ahora bien, este planteamiento leibniziano levanta dos objeciones. Por una parte, se nos presenta una ética remunerativo-punitiva que afecta al género humano, en cuanto que tiene la libertad de determinarse al bien haciendo uso de su razón, pero nuestra autonomía, en sentido literal, no nos permite convertirnos en nuestros propios legisladores, viéndonos moralmente obligados a obedecer la ley que el Legislador supremo ha tenido a bien comunicar a nuestra voluntad (Monadologie $\$$ 89: LEIBNIZ, 1978, VI, p. 622); tenemos una disposición natural a elegir bien y a actuar bien, por lo que nuestra libertad aumenta en la medida en que elegimos y actuamos conforme al principio de perfección. Por otra parte, es inherente a la limitación original del hombre estar inmerso, en muchas ocasiones, en pensamientos confusos: "El conocimiento distinto o la inteligencia tiene lugar en el verdadero uso de la razón; pero los sentidos nos suministran pensamientos confusos" (Teodicea \289: LEIBNIZ, 1978,VI, p. 288; LEIBNIZ, 2007, 10, p. 298); las criaturas inteligentes están sujetas a las pasiones, lo que les impide seguir a menudo el juicio del entendimiento (Teodicea \$310: LEIBNIZ, 1978,VI, p. 300; LEIBNIZ, 2007, 10, p. 308; cf. Necessity of faith, 1705: LEIBNIZ, 1948, p. 253), siendo la razón un motivo más entre otros a la hora de determinar la voluntad: "no obligo a la voluntad a seguir siempre el juicio del entendimiento, porque distingo este 
juicio de los motivos que proceden de las percepciones e inclinaciones insensibles" (Remarques sur le libre de l'origine du mal \$13; LEIBNIZ, 1978, VI, p. 413; LEIBNIZ, 2007, 10, p. 420). Este es un argumento que Leibniz emplea a menudo cuando se le acusa de obligar a la voluntad a seguir el juicio del entendimiento: “...Así el vínculo entre el juicio y la voluntad no es tan necesario como pudiera pensarse" (Teodicea $\ 311$; LEIBNIZ, 1978,VI, p. 301; LEIBNIZ, 2007, 10, p. 308), pero esto no implicaría sino una libertad por deficiencia en el hombre, de acuerdo con la definición positiva que ha facilitado, esto es, que el conocimiento racional del bien, se convierta en el motivo determinante de la elección. Sin embargo, Leibniz afirma que la prevalencia de las inclinaciones o pasiones no impide que el hombre sea dueño de sí, pues su imperio es el de la razón y sólo depende de él que sepa usar de su poder: "Sin embargo, esta prevalencia de las inclinaciones no impide que el hombre sea dueño de sí mismo, con tal que sepa hacer uso de su poder. Su imperio es el de la razón; no tiene más que prepararse con tiempo para oponerse a las pasiones y será capaz de detener la impetuosidad de las más furiosas." (Teodicea \$326; LEIBNIZ, 1978, VI, p. 309; LEIBNIZ, 2007, 10, p. 316; cf. carta a Coste, 19 Diciembre 1707: ; LEIBNIZ, 1978, III, p. 403). La más alta libertad es actuar según la soberana razón, como es el caso de Dios (Discours de Métaphysique \3; LEIBNIZ, 1978, IV, p. 429; Libertas est spontaneitas intelligentis: LEIBNIZ, 1978,VII, p. 109), pero puede entenderse en el planteamiento de Leibniz que esta libertad alcanza diferentes grados en el hombre que, no obstante, es libre porque tiene el poder de seguir la razón: “...la verdadera libertad es una de las más grandes joyas de la naturaleza humana, pero según la razón: la libertad no debe ser más que el poder de seguir la razón" (Carta a Burnett, 1701; LEIBNIZ, 1978, III, p. 278-279).

\section{La libertad como "pasaporte" para el reino moral de la gracia}

Como hemos visto en el apartado anterior, Leibniz subraya la diferencia fundamental que existe entre las "almas ordinarias" o "sensitivas" y los “espíritus” (Cf. LEINKAUF 2012, pp. 118ss.), caracterizados como "almas racionales" que "no son sólo un espejo del universo de las criaturas, sino también una imagen de la divinidad" (Principes \14; LEIBNIZ, 1978,VI, 
p. 604; LEIBNIZ, 2007, 2, p. 350; cf. Monadologie \83: ; LEIBNIZ, 1948, VI, p. 621), en tanto que por medio de la reflexión y del conocimiento de las ciencias son capaces de obrar en su propio ámbito con una creatividad similar a aquélla con la que Dios ha regulado arquitectónicamente el mundo (Cf. ROBINET, 1986). De esta manera, los seres poseedores de razón se distinguirían de manera esencial de los animales, elevándose por encima de las almas de los brutos para ingresar en una especie de sociedad con Dios, esto es, para formar parte de un mundo moral (el reino de la gracia), que no contravendría el mundo natural, sino que se situaría dentro de él pero transcendiéndolo.

Así, los seres humanos se convierten, en virtud de la razón y la libertad, en miembros de una sociedad gobernada por Dios, que constituye un mundo moral en el seno del mundo natural, en el cual no hay crimen sin castigo, ni buenas acciones sin recompensa, y donde se encuentra tanta virtud y felicidad como sea posible (Principes $\$ 15$; LEIBNIZ, 1948,VI, p. 604, y Monadologie $\$ S 84,85$ y 86). Esta ciudad de Dios o reino de la gracia constituye, desde mi punto de vista, la gran intuición leibniziana que permite considerar al hombre como un ser moral, en la medida en que reconoce la obra divina en una finalidad universal, sobre la que reposa el orden natural, y se decide a actuar haciendo buen uso de su razón, es decir, según el principio de lo mejor. Sin aislar al hombre de la naturaleza, la concepción leibniziana pretende elevarlo, por el privilegio de la conciencia reflexiva, a la dignidad de un ser dueño de sí mismo, de sus acciones y de su destino. La vida moral no puede entenderse sino como el progreso continuo hacia un ideal de perfección, de forma que el espíritu encuentre su felicidad en la determinación racional al bien (Nouveaux Essais II, 21, \42, LEIBNIZ, 1923,VI, 6, p. 194; Monadologie \ 90; LEIBNIZ, 1978,VI, p. 623). Pero este reino moral no implica la derogación del reino natural, sino que entre ellos existe una perfecta armonía, lo mismo que se daba entre los dos reinos naturales, el de las causas eficientes y el de las finales: "Al igual que hemos establecido anteriormente una armonía perfecta entre dos reinos naturales, el uno, de las causas eficientes, el otro, de las finales, debemos destacar aquí también otra armonía entre el reino físico de la naturaleza y el reino moral de la gracia, es decir, entre Dios, considerado como arquitecto de la máquina del universo, y Dios considerado como monarca de la ciudad divina de los espíritus. Esta armonía hace que las 
cosas conduzcan a la gracia por las mismas vías de la naturaleza y que este globo, por ejemplo, deba de ser destruido y reparado por vías naturales en los momentos en que lo requiera el gobierno de los espíritus para castigo de unos y recompensa de otros" (Monadologie \$S 87 y 88; LEIBNIZ, 1978, VI, p. 622; LEIBNIZ, 2007, 2, p. 341; cf. Teodicea \118: LEIBNIZ, 1978, VI, p. 168). La armonía universal permite así que no haya contradicción en admitir que las sustancias libres o inteligentes actúen por la sola espontaneidad de su propia potencia e interrumpan la conexión y el curso de las causas eficientes sobre la voluntad, a raíz de la intuición de alguna causa final, de forma que ninguna criatura sea capaz de predecir con certeza qué ha de elegir alguna mente conforme a las leyes de la naturaleza, del modo que a veces puede ser predicho qué ha de efectuar un cuerpo dado si el curso de la naturaleza no se interrumpe; del mismo modo que por la libre voluntad de Dios puede cambiarse el curso del universo, así se cambia por la libre voluntad de la mente el curso de sus representaciones (Verités nécessaires et contingentes, 1686, COUTURAT, 1902, p. 20); la armonía garantiza un orden universal en le que hasta los milagros tienen cabida, milagros "para nosotros", claro está (Discours de Metaphysique \$S 6, 7 y 16: LEIBNIZ, 1978, IV, pp. 431, 432 y 441).

Será precisamente su pertenencia al mundo moral de la gracia lo que le permita al hombre zafarse del determinismo natural -tal y como ocurrirá también en Kant (1989)-, siguiendo leyes más elevadas que el resto de los seres vivos, de forma que ningún cambio material pueda hacerle perder las cualidades morales de su personalidad (Système Nouveau de la Nature et de la Communication des Substances: LEIBNIZ, 1978, IV, p. 481). El espíritu humano es capaz de superar por medio del comportamiento racional no sólo el determinismo externo a que se ven sometidos los cuerpos, sino incluso el determinismo interno, psicológico que implica el comportamiento instintivo y que podría achacársele si poseyera únicamente espontaneidad, como el resto de las mónadas simples. Aunque no puede decirse que el hombre sea capaz de cambiar el curso de los acontecimientos, la razón introduce una perspectiva cualitativamente distinta, la del deber (Cf. ROLDÁN, 1994), que Leibniz identificará con la necesidad moral y que le permitirá al hombre otorgarse sus propios fines, con los que, no obstante, no hace sino cooperar a los fines divinos de la creación (Monadologie SS 87-90: LEIBNIZ, 1978,VI, pp. 622-623). 
A mi entender, el gran avance y originalidad del planteamiento leibniziano, lo que hará de él un ilustrado temprano (Cf.ANDREU, 2002) será dejar de considerar la libertad como un "poder hacer lo que se quiera" (libre albedrío) para empezar a definirla como "querer hacer lo que se debe" (verdadera libertad), es decir, determinarse racionalmente al bien. En Dios se presenta esta libertad de manera absoluta, pues su perfección moral le lleva a determinarse siempre hacia lo mejor, mientras que en los seres humanos se manifiesta sólo de forma relativa, al tomar sus decisiones contando con instintos y pasiones, e inclinándose siempre por aquello que le parece lo mejor. Sin embargo, será esta relatividad-que no relativismo-lo que permita a la libertad fundamentar una ética en los seres humanos, en cuanto que introduce una tensión entre el ser (sometimiento a pasiones e inclinaciones que se traduce en un conocimiento confuso) y el deber ser, que hace que el conocimiento reflexivo del verdadero bien se convierta en principio determinante de la acción humana, lo que le permite afirmar a Leibniz que el sabio actúa por principios y reglas (Teodicea $\$ \$ 28$ y 326: LEIBNIZ, 1978,VI, pp. 119 y 309).

Pero Leibniz no se limita a presentarnos en los lugares mencionados al reino de la gracia únicamente como un mundo moral, sino que establece una especie de analogía con el universo político, a la que he denominado en otro lugar (Cf. ROLDÁN, 1994) -en virtud de las concomitancias clásicas del término- "analogía de proporción”, en tanto que la esfera ética y la esfera política, tan divergentes en sus finalidades, son expresión en el pensamiento leibnizano de una misma idea: la de justicia universal, desarrollada por Leibniz de tal manera que la felicidad individual y el bien común acaben coincidiendo (Cf. RILEY, 2002).

Con otras palabras, lo que propugna el reino de la gracia leibniziano es la fusión de la ética y la política. Parafraseando al propio Leibniz: "En el individuo, la ética y la política no se pueden separar; y en el Estado, la política y la ética, tampoco. No se da un comportamiento verdaderamente justo ético-políticamente hablando, mientras el conjunto de actividades del individuo y de las diversas sociedades particulares no se ordenan y estructuran en favor del bien común del género humano. Es el principio arquitectónico general de la ciencia arquitectónica que es la política. Pues 'el principio de la justicia es el bien de la sociedad', entendiendo por sociedad la familia humana; es 'el bien general', el bien de 'la República 
universal de la que todos nosotros somos parte"' (Cf. ANDREU, 2002, p. 301). En efecto, para Leibniz la verdadera política debe fundamentarse en la ética, de manera que el provecho individual conduzca al bien común.

Ciertamente, resulta difícil delimitar con exhaustividad las fronteras que existen en el pensamiento de Leibniz entre la jurisprudencia, la ética y la política. Así, en ocasiones identifica ética y derecho natural-como ciencias de lo justo- (AUSÍN \& PEÑA, 2002), mientras a renglón seguido señala que la política-como ciencia de lo que es útil a la comunidad o de lo que es justo o equitativo- no podría llevarse a cabo sin la fundamentación antecedente de la ética (carta a Conring, 23-1-1670: LEIBNIZ, 1923, II, 1, p. 29; Nova Methodus: LEIBNIZ, 1923, VI, 1, pp. 300-301; Elementa juris naturalis: LEIBNIZ, 1923,VI, 1, p. 459), puesto que desde el punto de vista verdadero ambas ciencias, la del bien privado y la del bien público, se implican recíprocamente. El derecho se presenta así como puente entre la ética y la política, propiciando que el estado, con el monarca a la cabeza, en tanto que espejo de Dios por excelencia, actúe como mediador entre el bien privado y el bien público. Para ello, una de las principales tareas que deberá acometer el príncipe será la de la educación de sus súbditos, para conseguir un equilibrio entre los intereses privados y los de la comunidad.

En cualquier caso, el sentido de la teoría y actividad políticas leibnizianas implica reconocer su fundamento en una ética -O "jurisprudencia universal"-, cuya finalidad no sería otra que perseguir la utilidad general o el bien común (Cf. SCHNEIDERS, 1978). Con otras palabras, el verdadero político debe esforzarse por ajustar su tarea al ,ideal del sabio“(Cf. ROLDÁN, 2002 a), aplicando razón y orden en el discurrir contingente de la historia, tal y como escribió en 1701 a Thomas Burnet de Kemney: "el fin de la ciencia política debe ser hacer florecer el imperio de la razón" (LEIBNIZ, 1978, III, p. 277). Intereses universales que dibujan claramente el ,ideal del sabio“, en el que deben converger tanto el verdadero político como el verdadero científico: el principio ético de que la búsqueda de bienes individuales sólo es lícita si redunda en la utilidad común. De esta manera, Leibniz postula la perfectio universi como fin de la ética y de la ciencia jurídica (Cf. HEINEKAMP, 1969, p. 95) para que todos los seres humanos estén en condiciones de alcanzar la felicidad (Cf. SCHEPERS, 1962, p. 185). Así pues, hay que ver este ideal de la "caridad del sabio" (Cf. 
RILEY, 1972), que se plasma en los esfuerzos concretos de Leibniz por fundar por toda Europa (Cf. ROLDÁN, 2002 a) Academias científicas, como un medio para instaurar en el mundo la "república universal de los espíritus", para que se puedan reconocer, por encima de los intereses egoístas, la empresa ético-política por la que deben esforzarse: la instauración de la "justicia Universal".

${ }^{1}$ Este trabajo se ha realizado en el Intituto de Filosofia del CSIC, en el marco de proyecto de investigación "Leibniz en español 2" (FFI2010-15914).

${ }^{2}$ Esta es una idea que vertebra toda la reflexion leibniziana sobre la libertad, estando ya presente en sus escritos de juventud (LEIBNIZ, 1990 e ROLDÁN 1990). Como botón de muestra, pueden consultarse: Confessio philosophi (LEIBNIZ, 1923,VI, 3, p. 127), Definición de libertad (LEIBNIZ, 1978, VII, p. 108; LEIBNIZ, 1990, p. 207), De libertate (1677; LEIBNIZ, 1948, p. 273), Conversation sur la liberté et le destin (aprox. 1699-1703, LEIBNIZ, 1948, p. 478), o Verdades necesarias y contingentes (1686; COUTURAT, 1902, p. 17).

${ }^{3}$ Una afirmación que aparece tanto en una obra relativamente temprana como el Discurso de metafisica ( $(13$, LEIBNIZ, 1978, IV, p. 438-439), como en la mayor expresión de la madurez de su sistema, la Monadología (\$ 46, LEIBNIZ, 1978,VI, p. 614), y en su correspondencia: cf., por ejemplo, la Carta a Bourguet, del 11 de Abril de 1710 (LEIBNIZ, 1978, III, p. 550).

${ }^{4}$ Cf. CRESSON, 1903, p. 288. En este sentido, me parece un grave error de GABAUDE, 1970-74, la afirmación de que todas las mónadas poseen libertad:"...en attribuant les facteurs de la liberté à toute monade, Leibniz adopte une position naturaliste et anticartésienne". Esta aserción contradice la tesis leibniziana de que la libertad implica elección y deliberación, cosa que no todas las mónadas poseen.

\section{Referências bibliográficas}

ADAMS, R. 1994. Leibniz, Determinist, Theist, Idealist, New York: Oxford.

AGUADO, J. 1993. Todo pasa como si... no La simulación en la filosofía de Leibniz, Revista de Filosofía,Vol. 9.

AGUADO, J. 2002. Campo de validez del principio leibniziano de razón, en Ciencia, tecnología y bien común: la actualidad de Leibniz, A. Andreu, J. Echeverría y C. Roldán (eds.), Valencia: UPV, 91-106.

ANDREU, A. 2002. El principio arquitectónico de Leibniz en Ética y en política, en Ciencia, Tecnología y bien común, en Ciencia, Tecnología y bien común, loc. cit. 299-319. 
ARANA, J. 2005. Los filósofos y la libertad, Madrid: Síntesis.

AGUSTÍN, San. 1946. De civitate Dei, texto latino y castellano en B.A.C. AUXIN, Tx. \& PEÑA, L. 2002. Derecho y bien común en Leibniz, en Ciencia, Tecnología y bien común, loc. cit., 320-339.

AUXIN,Tx. \& ROLDÁN, C. 2006. Leibnizian basis for intercultural dialogue, en Formes de rationalité et dialogue interculturel, F. Triki, Tx. Ausín, R. Parellada \& V. Serrano, (eds.), Hildesheim: Georg Olms, 83-102.

AXELOS, Ch. 1973. Die ontologischen Grundlagen der Freiheitstheorie von Leibniz. Berlin: Walter de Gruyter.

BARUZI, J. 1907. Leibniz et l'organisation religieuse de la terre d'après des documents inédits. Avec un fac-simile, Paris: Alcan.

COUTURAT, L. 1901. La logique de Leibniz, Paris: Alcan.

-1902. Sur la métaphysique de Leibniz, Revue de Métaphysique et de morale, $\mathrm{X}, 1-25$.

CRESSON, A. 1903. De libertate apud Leibnitium. Paris: Alcan.

ECHAVARRÍA, A. 2010 Metafísica leibniziana de la permisión del mal, Navarra: EUNSA.

GABAUDE, J.M. 1979-74. Liberté et raison (3 vols.). Toulouse: Univ. Toulouse-Le Mirail.

GRUA, G. 1953. Jurisprudence universelle et théodicée selon Leibniz. Paris: PUF.

HEINEKAMP, A. 1969. Das Problem des Guten bei Leibniz, Bonn: Bouvier u. COVerlag.

KULSTAD, M. 1991. Leibniz on Apperception, Conciousness and Reflection, München.

LEIBNIZ, G. W. 1854. Réfutation inédite de Spinoza par Leibniz, pécédée d'une mémoire par A. Foucher de Careil, Paris. 
1903 (reimpr. 1699). Opuscules et fragments inédits de Leibniz, extraits des manuscrits de la Bibliothèque Royal de Hanovre par Louis Couturat, Paris: Hildesheim.

1923. Sämtliche Schriften und Briefe, hg. von der

Preussischen, bzw. Deutschen Akademie der Wissenschaften zu Berlin. Darmstadt. (Leipzig, 1938, Berlin 1950 ss)

1948. Leibniz. Textes inédits, d'aprés les manuscrits de la Bibliothèque Provincial de Hanovre, Publius et anotés par Gaston Grua, Paris (2 vols.).

1978. Die philosophischen Schriften, hg. von C.I.

Gerhardt, Berlin, 1875-90. Reimpr. Hildesheim: Georg Olms (7 vols.). 1967. Confessio Philosophi, Frankfurt am M. 1982. Escritos filosóficos. Buenos Aires: Charcas. 1990. Leibniz: Escritos en torno a la libertad, el azar y el destino. Madrid:Tecnos. .2007- . Obras filosoficas y cientificas, Granada: Comares.

LEINKAUF,Th. 2012. Einheit, Natur, Geist. Beiträge zu metaphysischen Grundproblemen im Denken von Gottfried Wilhelm Leibniz, Frankfurter Kulturwissenschaftliche Beiträge, Band 13, Berlin: trafo.

LUNA ALCOBA, M. 1996. La ley de continuidad en G.W. Leibniz. Universidad de Sevilla.

NICOLÁS, J.A. 1993. Razón, verdad y libertad en G.W. Leibniz, Universidad de Granada. 1995. Formulación del principio de razón en G.W. Leibniz, en Saber y conciencia, J.A. Nicolás y J. Arana (eds.), Granada: Comares. NELLI, S. 1982. Determinismo e libero arbitrio da Cartesio a Kant.Turin. PARKINSON, G.H.R. 1970. Leibniz on Human Freedom, Wiesbaden. POSER, H. 1969. Zur Theorie des Modalbegriffs bei G.W. Leibniz, Wiesbaden. 
RACIONERO, Q. 2013. La noción de "libertad racional" en Leibniz y sus consecuencias para el problema del mal, en Pensando la religión, J. San Martín y J.J. Sánchez (eds.), Madrid:Trotta/UNED, 412-447.

RILEY, P. 1972. Leibniz's Universal Jurisprudence: Justice as the Charity of the Wise, Cambridge: Harvard Univ. Press.

2002. Leibniz and the Idea of the Common Good, en Ciencia, Tecnología y bien común, en Ciencia, Tecnología y bien común, loc. cit., 357-364.

ROBINET, A. Architectonique disjonctive, automates systémiques et idéalité transcendentale dans l'oeuvre de G.W. Leibniz, Paris.

ROLDÁN, C. 1984. Crítica de Leibniz al determinismo absoluto de Spinoza, Revista de Filosofía del CSIC, 7, 327-338.

- 1989 a. Das Vollkommenheitsprinzip bei Leibniz als Grund der Kontingenz, Studia Leibnitiana vol.2, 188-195.

1989 b. Leibniz: preludio para una moral de corte kantiano, en Kant después de Kant R.R. Aramayo y J. Muguerza (eds), Madrid: Tecnos, 341-348.

1990.b. La salida leibniziana del laberinto de la libertad, Introducción a Escritos en torno a la libertad, el azar y el destino. Madrid: Tecnos, IX-LXXVII.

1994. Del deber ser al ejercicio del poder (las analogías del mundo moral y el político), en G.W. Leibniz, Analogía y expresión, Q. Racionero y C. Roldán (eds), Madrid: Universidad Complutense, 431-442.

1997 (2 $2^{\mathrm{a}}$ ed. 2005). Entre Casandra y Clío, una historia de la filosofía de la historia. Madrid: Akal.

1999. El hilo de Ariadna de la determinación racional, Studia Leibnitiana 34, 55-68.

- 2002 a. El ideal del sabio en la construcción de la Europa moderna“, Ciencia, Tecnología y bien común, loc. cit., 378-388. 
- 2002 b. Geschichtsphilosophie: ein problematisches Erbe der Aufklärung, en Neuzeitliches Denken, G. Abel, H-J. Engfer y Ch. Hubig (eds.), Berlin-New York: Walter de Gruyter, 285-304.

2005. ¿Qué queda de la filosofia de la historia de la Ilustración?, en La compresión del pasado, M. Cruz y D. Brauer (eds.), Barcelona: Herder, 187-216.

- 2009. Ilustración y semántica histórica: el protagonismo de Leibniz, en Teorías y prácticas de la historia conceptual, F. Oncina (ed.), Madrid: Plaza y Valdés, 393-422.

ROLDÁN, C. y MORO, O. 2009. Aproximaciones a la contingencia. Madrid: Catarata.

- 2013. Teodicea y libertad en Leibniz: del mal radical al bien común, en Pensando la religión, J. San Martín y J.J. Sánchez (eds.), Madrid: Trotta/UNED, 448-461.

ROVIRA, R. 2010. Si quidem Deus est, unde mala?, en Anuario Filosófico XLIII/1.

RUANO,Y. 2008. “Sobre excesos, olvidos y perversiones de la razón”, en Occidente: razón y mal, en Y. Ruano y J. Muguerza (eds.), Madrid: Fundación BBVA, 168-173.

RUTHERFORD, D. \& COVER, J. (eds.). 2005. Leibniz. Nature and Freedom, New York: Oxford University Press.

SAAME, O. 1961. Der Satz vom Grund bei Leibniz, Mainz.

SALAS, J. de. 1967. El conocimiento del mundo externo y el problema crítico en Leibniz y en Hume, Universidad de Granada.

SALAS, J. de. 1994. Razón y legitimidad en Leibniz, Madrid:Tecnos.

SCHEPERS, H. 1962. Glück durch Wissen. Zur Bestimmung des Philosophen durch Leibniz, en Archiv für Begriffgeschichte, Bd. XXVI, 184-192.

SCHNEIDERS, W. 1978.Vera Politica. Grundlagen der Politiktheorie bei G.W. Leibniz, en Recht und Gesellschaft, ed. por F. Kaulbach y W. 
Krawich, Münster, 589-604.

SOTELO, I. 1995. Notas sobre el problema del mal, en Cristianismo e Ilustración, M. Fraijó y J. Masía (eds.), Madrid: UPCO.

SPINOZA, Baruch de, Opera, hg. von Carl Gebhardt, Heidelberg, 1925 (4 vols)

TORRALBA, J.M. 2005. La libertad posible. Acerca de la noción leibniziana de "inclinar sin necesidad", en Anuario filosófico XXXVIII/1, 279-290. 